Paper ID \#20575

\title{
Work in Progress: Curriculum Revision and Classroom Environment Re- structuring to Support Blended Project-Based Learning in First-Year Gen- eral Engineering Laboratory Courses
}

\section{Prof. Brandon B. Terranova, Drexel University}

Dr. Terranova is an Assistant Teaching Professor in the College of Engineering at Drexel University. In his current role, he is the lead instructor for the freshman engineering program, and oversees activities in the Innovation Studio, a large-area academic makerspace. He has taught and developed courses in general engineering and mechanical engineering at Drexel. Prior to Drexel, he has taught and developed courses in physics and mathematics at SUNY Binghamton, University of Delaware, Missouri Online College, and St. Mark's High School. Dr. Terranova's research interests include plasmonics, optical tweezing, photonics, electromagnetism, and engineering education. He received his MS in Physics from SUNY Binghamton, and his PhD in Electrical Engineering with a concentration in Electrophysics from Drexel University for his work in 3D plasmonic nanostructures.

Prof. Christopher M. Weyant, Drexel University (Eng. \& Eng. Tech.)

Dr. Weyant has been an Associate Teaching Professor in the Department of Materials Science and Engineering at Drexel University since 2011. Prior to this position, he was an Assistant Professor of Materials Science and Engineering at Stony Brook University. He earned his doctorate from Northwestern University, master's from the University of Virginia and his bachelor's from Pennsylvania State University. In addition to his experience in academia, Dr. Weyant has worked at Honeywell Aerospace, Capstone Turbine Corporation and Sandia National Laboratories.

Prof. Steven Wrenn, Drexel Unviersity, Chemical and Biological Engineering Department

Prof. Youngmoo Kim, Drexel University, ExCITe Center

Youngmoo Kim is director of the Expressive and Creative Interaction Technologies (ExCITe) Center and an associate professor of electrical and computer engineering at Drexel University. He also serves as Resident Technologist for Opera Philadelphia. He received his Ph.D. in media arts and sciences from MIT in 2003 and also holds master's degrees in electrical engineering and music (vocal performance practice) from Stanford University as well as a B.S. in engineering and a B.A. in music from Swarthmore College. His research group, the Music \& Entertainment Technology Laboratory (MET-lab), focuses on the machine understanding of audio, particularly for music information retrieval. Honored as a member of the Apple Distinguished Educator class of 2013 and the recipient of Drexel's 2012 Christian R. and Mary F. Lindback Award for Distinguished Teaching, Youngmoo also has extensive experience in music performance, including eight years as a member of the Boston Symphony Orchestra's Tanglewood Festival Chorus.

\section{Dr. Lunal Khuon, Drexel University}

Dr. Lunal Khuon is an Associate Clinical Professor at Drexel University in the Engineering Technology (ET) Department. He also serves as the Assistant Department Head for Graduate Studies and Director of Research for the ET Department, as well as oversees the Biomedical Engineering Technology concentration. Prior to Drexel, Dr. Khuon had previously held design and system positions at Texas Instruments, Motorola, Hughes, and IBM and faculty positions as an Assistant Professor at Villanova University and Delaware State University and an adjunct Assistant Professor at the University of Pennsylvania. His research interests are in radio frequency and analog integrated circuit design, embedded systems, biomedical electronics, and engineering education. He received his Ph.D. in Electrical Engineering and Computer Science from MIT.

Miss Kristin Imhoff, Drexel University (Eng. \& Eng. Tech.)

Kristin Imhoff graduated from Drexel University with her Bachelor's in Mechanical Engineering in 2009. She began her career at Drexel in 2009 as an academic advisor for the Mechanical Engineering \& Mechanics department, serving as a professional academic advisor to over 550 students. In January 2012, 
she became the Program Manager for Assessment \& Retention for the College of Engineering, coordinating assessment and accreditation efforts for 12 ABET-accredited undergraduate programs and an ACCE accredited program. She created the Academic Center for Engineers (ACE) in the Spring of 2013 to provide tutoring support for engineering courses. She was promoted to Associate Director for Assessment \& Retention Projects in July 2015. Kristin has completed Drexel's Supervisory Certificate Program and ABET's IDEAL Scholar program and is currently working toward completion of an M.S. in Human Resource Development and a second Bachelor's in Anthropology. She is a member of ASEE and SHRM.

\section{Mr. Kevin Ayers, Drexel University (Eng. \& Eng. Tech.)}

Kevin Ayers is the Database Manager for the College of Engineering at Drexel University, handling all data analysis and data reporting needs across the College. In addition to reporting on the state of the College to all external entities (e.g. ASEE \& U.S, News \& World Report), he has created dozens of information management systems that allow the College to track resource utilization, physical inventory, and student engagement, persistence, and quality. His previous position as Director of Operations and Logistics for the College of Engineering allows him to bring a unique perspective and insight into how to best display and use the data that both the College of Engineering and Drexel University collect.

\section{Dr. Antonios Kontsos, Drexel University (Eng. \& Eng. Tech.)}

Antonios Kontsos joined the Mechanical Engineering \& Mechanics Department at Drexel University in September 2009 and he is currently the Director of the Theoretical and Applied Mechanics Group (TAMG). He received his undergraduate 5-year Diploma (2002) from the Department of Mechanical Engineering and Aeronautics at University of Patras (Greece), and his MS (2005) and PhD (2007) degrees from the Department of Mechanical Engineering and Materials Science at Rice University (Houston, TX). He also held a 2-year Post-doc position at the Center for Mechanics of Solids, Structures and Materials in the Aerospace Engineering \& Engineering Mechanics Department at the University of Texas at Austin (Austin, TX). Kontsos is a member of the ASME, ASNT and Sigma Xi societies and he is serving as the Faculty Advisor of the local ASME student chapter at Drexel University

\section{Leonid Hrebien, Drexel University (Eng. \& Eng. Tech.)}

Leonid Hrebien received his BS degree in electrical engineering, MS degree in biomedical engineering, and Ph.D. degree from Drexel University, Philadelphia, PA in 1972, 1975 and 1980 respectively. He is Professor of Electrical and Computer Engineering at Drexel University, a Senior Member of IEEE and a Fellow of the Aerospace Medical Association. His research interests are in the areas of biomedical systems, the study and mitigation of acceleration effects on cardiovascular and cerebrovascular functions and the analysis, modeling and estimation of large arrays of complex and noisy biological signals and data. Currently he serves as Interim Director of the Engineering Core Curriculum at Drexel University.

\section{Prof. James E. Mitchell, Drexel University (Eng. \& Eng. Tech.)}

Biography of Professor James E. Mitchell, AIA - Associate Dean, Professor, Civil, Architectural and Environmental Engineering - Drexel University

Professor Mitchell draws on 28 years of experience at Drexel and 15 years before that as an Architect, including being a principal in two design firms. At Drexel he's now Associate Dean for the second time and has been CAEE interim department head and longtime director of the Architectural Engineering program. He was educated at Harvard (BA, and MS in Fluid Mechanics) and UPenn (MArch).

His professional interests are in teaching design, the use of information technology in education, and education generally. . 


\title{
Work in Progress: Curriculum Revision to Support Blended Project- Based Learning in First-Year General Engineering Laboratory \\ Courses
}

\begin{abstract}
This work-in-progress report details the restructuring of a three-quarter first-year general engineering laboratory course sequence ending in a term-long cornerstone design project. Motivated by a taskforce implemented in 2015 to improve the first-year common curriculum, this development effort affects the first two quarters of this three-quarter, first-yearprogram laboratory course sequence. Faculty representatives from all engineering departments in the college were assembled to address three goals. The first goal was the establishment of a course structure emphasizing professional skills and engineering design. Second was the creation of a database of "mini-projects" to be integrated into the new course structure. The third goal was the establishment of a blended learning environment which uses web-based lectures and assessments in conjunction with hands-on, problem-based-learning laboratory activities. Three design-focused mini-projects were piloted during the fall and winter quarters of the 2016-2017 academic year. A professional skills-focused "micro-project" ran for the first three weeks of the fall quarter, followed by seven weeks of a design-focused "mini-project". Pilot sections in the winter quarter began with a different seven-week mini-project followed by three weeks of another professional skills-focused micro-project. The first three mini-projects developed for this effort were titled: Robot Instruments, Heat Engine, and the Supercap Car Challenge. During the fall and winter quarters, students in the pilot sections were given self-efficacy surveys before and after their projects based on a Likert-type scale. These gauged their impressions of the projects, and self-evaluated their relevant knowledge and abilities before and after the projects. Early results presented in this paper indicate an improved level of student satisfaction with the new course structure and the pilot mini-projects.
\end{abstract}

\section{Introduction}

The goal of introductory general engineering laboratory courses is to engage, challenge and excite first-year students about engineering. This report discusses the restructuring of a threequarter general engineering laboratory course sequence (ENGR 101/102/103) to ensure these goals are met, while improving soft skills and student understanding of engineering concepts. The effort, guided by faculty representatives from each department in the college, included the development of two professional skills-focused problem based learning (PBL) micro-projects (MPs) and three design-focused seven-week mini-projects (7WMPs). The paper highlights these efforts, presents student assessment data used to evaluate the success of the pilot offering and outlines future steps based on the lessons learned.

\section{Literature review}

A student's decision to continue in the field of engineering reaches a critical point during their first year. ${ }^{1,2,3}$ There are many factors that go into undergraduate student success. In addition to 
the preparedness of the student and attitudes about science, math, and engineering ${ }^{4}$, psychological $^{5}$, sociological ${ }^{5}$, environmental ${ }^{6,7}$, and personality ${ }^{8}$ factors influence student persistence in engineering. Much research has gone into the topic of student success and retention at the undergraduate level, and it has been found that in addition to prior demonstration of academic success (e.g., high school GPA, SAT scores, and other academic achievements), a main factor in determining student success at the college level was student motivation. ${ }^{9}$

In an effort to enhance student motivation, some engineering schools have made changes to their program's digital and physical infrastructure to keep up with the rapidly evolving technologies and learning styles of the modern engineering student. For example, New Mexico State University (NMSU) has implemented a new first year program at their institution, with a focus on PBL, flipped classroom instruction, and peer mentoring. ${ }^{10}$ Programs such as this have shown that changes to the digital and physical infrastructure driven by ABET requirements and student feedback have led to an increase in student confidence, subsequently leading to improved retention rates. ${ }^{11,12}$

\section{The evolution of the first-year engineering program at Drexel University}

Design is a difficult topic to teach, and also difficult for first-year engineering students to gain proficiency in, due to the complex and creative process of engineering design. The design process has been a focal point for the first-year engineering program at Drexel University since 1988 because it simultaneously integrates experience with multidisciplinary projects, scientific concepts, project management, and other professional skills using a PBL approach. In addition, the impetus for design education in the first year of an undergraduate engineering education is to prepare students for future design projects, and that industry expects engineers to understand the design process. ${ }^{13}$

Drexel introduced design as a unifying theme for first-year engineering students in 1988 as the heart of its NSF-Funded $\mathrm{E}^{4}$ program. ${ }^{14}$ That experiment initially worked with a cohort of 100 students. It was assessed continuously and expanded to four 100-student cohorts over its fouryear lifetime. In 1993 it was adopted by faculty vote as the curriculum for all engineering students in the first two years. ${ }^{15}$ In the years since, the curriculum has evolved with changes in the institution, but student exposure to engineering design through the first year has remained constant.

\section{Description of the new program}

The College of Engineering formed a taskforce in 2015 to identify areas of emphasis in the firstyear engineering program to ensure the undergraduate students were receiving an education to prepare them to become engineers in modern-day society. Table 1 outlines the results of this taskforce, and the areas of emphasis were used as a basis for the changes implemented in a new version of ENGR 101, piloted in three sections during fall term of 2016 in which there were 110 students. 
Table 1: First-year engineering laboratory course sequence areas of emphasis.

\begin{tabular}{|c|c|}
\hline \multirow{14}{*}{ 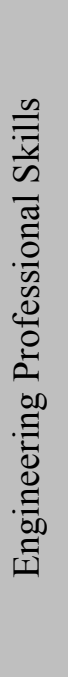 } & Technical communication, organization and presentation. \\
\hline & Ability to work in teams. \\
\hline & Time management and planning. \\
\hline & Professional skills for co-op (resume, interviews, etc.). \\
\hline & Project management (manage tasks, budget, etc.). \\
\hline & How to use research resources. \\
\hline & How to critically evaluate information (found online, in books, articles, etc.). \\
\hline & Ability to interact with a diverse audience. \\
\hline & $\begin{array}{l}\text { Understand societal factors impacting engineering (aesthetics, ethics, sustainability, } \\
\text { manufacturability, etc.). }\end{array}$ \\
\hline & The business cycle of engineering; role of entrepreneurship. \\
\hline & Different engineering disciplines. \\
\hline & Ability to define engineering project success and/or performance enhancement. \\
\hline & Ability to adjust to different cultures and understand different global needs and constraints. \\
\hline & Understand role of research in engineering; gain experience in research. \\
\hline \multirow{12}{*}{ 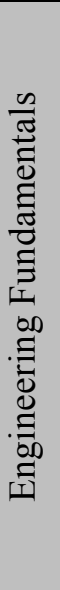 } & Programming and logical thinking. \\
\hline & Use of mathematics in the design process. \\
\hline & Use of basic science in the design process. \\
\hline & Integration of science into the design process. \\
\hline & Ability to decompose problems into sub-problems. \\
\hline & Ability to define tasks in a systematic manner. \\
\hline & $\begin{array}{l}\text { Understand limits of measurement, basic statistical analysis, error and uncertainty, and } \\
\text { interpretation of data. }\end{array}$ \\
\hline & Use various measurement and fabrication tools and technologies. \\
\hline & Understand the design process. \\
\hline & Use CAD, modeling, and/or visualization tools. \\
\hline & Ability to do and to design experiments, gather data, analyze, report and present data. \\
\hline & Understand relationships between inputs and outputs in systems. \\
\hline
\end{tabular}

The remaining sections of ENGR 101 (15 total sections/678 students) kept the current version of the first-year engineering design curriculum. These students attended one 50-minute lecture on Monday ( $\sim 170$ students in each section) and then one 2-hour lab section later in the week ( 48 students). Lectures focused on topics relevant to engineering design, their lab projects and project planning. During lab in the first seven weeks, students worked on the design of a Rube Goldberg machine with design constraints. In the final three weeks, students worked on an engineering design module where they chose one of five design problems and created a plan to solve the problem. This plan involved creating a Gantt chart, budget and bill of materials.

Shortly after the conclusion of the taskforce, a workgroup was formed to incorporate these changes in a reformulation of the first-year laboratory course sequence. The changing learning styles and expectations of today's first-year students were considered, and a flipped classroom model was chosen to complement new PBL, design-focused, 7WMPs. In addition, to educate the students in the professional skills outlined in Table 1, two separate three-week MP modules were developed that all students would complete in addition to completing two 7WMP modules during their first two quarters as first-year students in ENGR 101 and ENGR 102. 
Therefore, based on the ABET criteria student outcomes a-k (as currently defined), and the areas of emphasis identified in Table 1, the workgroup introduced updated course learning objectives (CLOs) for ENGR 101 and ENGR 102:

Students will be able to...

1. describe the engineering design process (e).

2. use the engineering design process to work through an engineering problem $(\mathrm{a}, \mathrm{b}, \mathrm{c}, \mathrm{e}, \mathrm{k})$.

3. describe and use techniques for successful team management (d).

4. use analytical and computational modeling and/or visualization tools to describe the activities, tools and products of working engineers $(\mathrm{k})$.

5. describe distinguishing characteristics among College of Engineering majors (h).

6. make measurements and analyze engineering data taking into consideration limits of measurement, uncertainty and errors (b).

7. demonstrate effective technical communication in oral, visual and written forms $(\mathrm{g})$.

The new course structure is outlined in Table 2, and is similar in structure to a model developed at Villanova University. ${ }^{16}$ The first MP (MP1) is common to all first-year students, and is completed during the first three weeks of ENGR 101 (taken in the fall quarter). Following this in weeks 4 through 10, students will complete a 7WMP for the duration of the fall term based on which section they are enrolled in. During the winter quarter, students start off in a different 7WMP for the first 7 weeks, and finish the winter term by completing MP2 in weeks 8 through 10, which is also common to all students in ENGR 102.

Table 2: Overall organization of micro-projects and mini-projects in ENGR 101 and ENGR 102.

\begin{tabular}{|l|l|l|}
\hline \multicolumn{2}{|c|}{ ENGR 101 (1 } & Quarter) \\
\hline Weeks 1-3 & $\begin{array}{l}\text { Micro-project I } \\
(\text { MP1 })\end{array}$ & $\begin{array}{l}\text { Professional skill building } \\
\bullet\end{array}$ \\
\hline Weeks 7-10 & $\begin{array}{l}\text { Mini-project I } \\
(7 W M P 1)\end{array}$ & $\begin{array}{l}\text { One of the following: } \\
\text { 1. Robot Instruments } \\
\text { 2. Heat Engines } \\
\text { 3. Supercap Car Challenge }\end{array}$ \\
\hline Weeks 1-7 & $\begin{array}{l}\text { Mini-project II } \\
\text { (7WMP2) }\end{array}$ & $\begin{array}{l}\text { One of the following (cannot } \\
\text { repeat ENGR 101 project): } \\
\text { 1. Robot Instruments }\end{array}$ \\
& & $\begin{array}{l}\text { 2. Heat Engines } \\
\text { 3. Supercap Car Challenge }\end{array}$ \\
\hline Weeks 8-10 & $\begin{array}{l}\text { Micro-Project II } \\
\text { (MP2) }\end{array}$ & $\begin{array}{l}\text { - Professional skill building } \\
\text { Engineering Systems Design }\end{array}$ \\
\hline
\end{tabular}

In addition to the reorganization of the course and introduction of micro- and mini-projects, the face-to-face lecture component with a large group of students was eliminated in the pilot sections. Instead, online pre-lab lectures and activities were moved onto the course learning management system (LMS), Blackboard Learn. Although development of these online 
components do add to the preparation time for the course, after their development, they will be available for future use. Traditionally, the face-to-face lecture was led by the overall course coordinator with lab sections being run by laboratory instructors. In the pilot sections, the students only have face-to-face time in lab with the lab instructor. Therefore, contact time with this instructor is the same for both versions of the course. The materials for the pilot sections were developed by the respective lab instructors. This course development did require extra time but after the materials were created, the amount of time spent for preparation in the future will be approximately the same as in the regular sections.

\section{Micro-projects}

Although the first-year engineering design laboratory course sequence is focused on inspiring students to be creative and innovative as engineers, laying the foundation for building crucial professional skills is also a priority. Engineers must be able to work effectively on a team, find relevant literature and documents efficiently, and communicate their technical work both in oral and written form. To lay the foundation for these skills, the first three weeks of ENGR 101 were devoted to not only introducing engineering design to students but also having them work on activities designed to give them their first exposure to professional skill building in an engineering environment.

Each of the three weeks was specifically devoted to the building of one professional skill with online activities designed to enhance their skills as an individual and in-lab activities designed to enhance these skills as a team. Each week, through Blackboard Learn, students watched lectures, took quizzes, and completed exercises including an oral presentation and technical writing assignment prior to attending lab. As seen in Table 2, the first week introduced the concept of engineering design and ways to be an effective team member. The second week focused on technical oral presentations and engineering disciplines. The third week focused on technical writing and information literacy. These weekly themes carried over into the laboratory activities.

The primary engineering laboratory design activity which reinforced the professional skill development over the first three weeks was the building of a straw tower. Working in groups of 3 or 4, students had to first design a tower made from straws, paper clips, masking tape and/or paper. Each supply was given a cost and a $\mathrm{CO}_{2}$ emission value. The first goal was to build the highest tower for the cheapest cost which would not topple over in the presence of "wind" from a fan. Students designed their tower and created a bill of materials in week one. They built their first iteration of their tower in week 2 . In week 3, they built a second iteration of their tower based on what they learned from weeks 1 and 2 while also considering the environmental impact of their tower. Environmental impact was calculated by summing the $\mathrm{CO}_{2}$ emission value for each of their supplies. During each of the build weeks, teams could purchase additional supplies at twice the cost, and they could not return any supplies that were ordered through their bill of materials for each iteration. During weeks 2 and 3, there were also team oral presentations and written assignments based on their tower designs.

During the last three weeks of ENGR 102, a common curriculum will also run through all sections with the professional skill building focused on project management and engineering 
ethics. In addition, activities will prompt students to reflect on their experiences during their two 7WMPs and how they might impact their decisions on future engineering design projects.

Specifically, student groups will choose from a selection of design scenarios for which they will have to come up with a solution on paper. As part of the exercise, they will reflect on what they have learned and how that can be applied to the new project. New information regarding initial project planning will be provided and applied. Each of the design scenarios will have accompanying engineering ethical dilemmas which will be explored and discussed. The final week of the quarter will involve an oral presentation with accompanying visuals to describe their design solution, how their previous projects impacted their decisions, and how they addressed the ethical concerns.

Students were assessed as individuals using the online quizzes, oral presentation and written assignment during the MPs. Students were also assessed as a team through the submission of their engineering design and bill of materials, oral presentation after their first build and a written assignment after their second build in ENGR 101. Additional assessment in ENGR 102 will occur based on written and oral assignments. Students were also required to assess their teammates after the first three weeks of ENGR 101 in order to determine each student's contribution to the micro-project. With the simple straw tower project, students could be creative and implement concepts of engineering design without strict technical guidelines. The project allowed them to focus on team building as well as exploring how technical communication is different than other types of communication from both individual and team perspectives. The assignments in the final three weeks of ENGR 102 will give an opportunity for metacognition with the goal of students being able to apply their experiences in ENGR 101 and 102 to engineering projects in ENGR 103 and beyond.

\section{Seven-week mini-project descriptions}

Below is a description of the three 7WMPs run in ENGR 101 during the fall quarter of the 20162017 academic year. Each were run in a single lab section with up to 48 students per section during weeks 4 through 10 after the three-week MP1.

\section{Robot Instruments 7WMP:}

This module provides an introduction to robotic (computer-controlled, physically-actuated) systems with the unique objective of creating a functional self-playing musical instrument. In pursuing this goal, students are expected to achieve the following engineering learning outcomes:

1. Gain an understanding of microcontrollers (specifically, Arduino-based platforms), what they are useful for, and how to control external devices (motors and other physical actuators) through coding.

2. Learn to implement basic circuits using a breadboard, including how to provide adequate external power for high-power actuators (certain motors, solenoids, etc.).

3. Design and fabricate (using laser cutting, 3D printing, CNC milling, etc.) a simple component that extends the capabilities of a basic electro-mechanical system. 
4. Demonstrate a working, integrated digital-physical systems project that combines electrical and mechanical components to produce sound.

The instruments designed by students over this 7WMP, range from simple servo-controlled percussion (e.g., xylophones and chimes) to highly complex fingering and strumming systems for stringed instruments. Figure 1 depicts a self-playing ukulele with a 3D-printed rotating block to "finger" different chords.

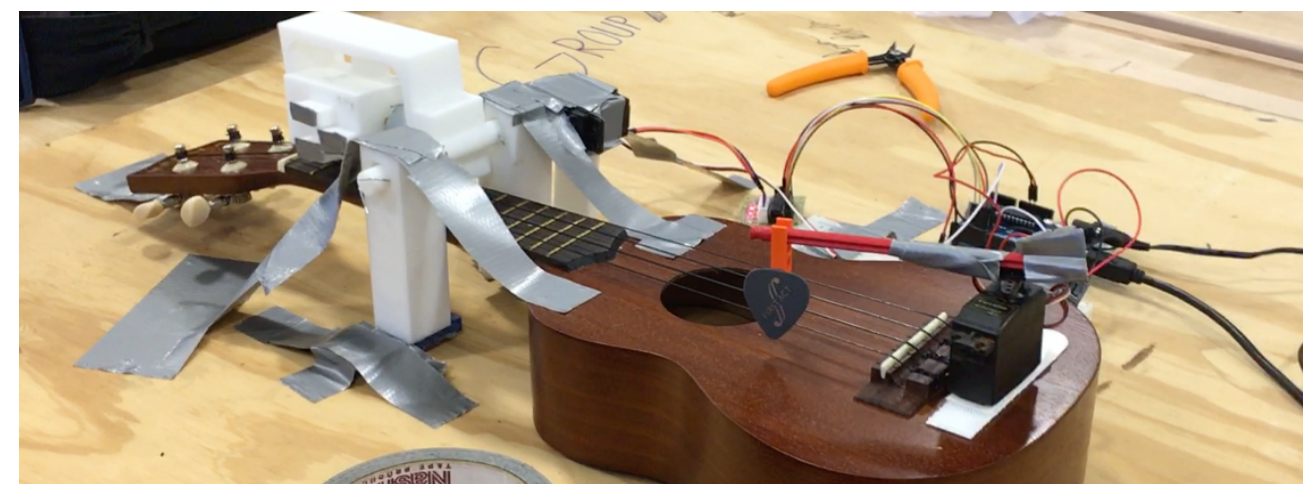

Figure 1: Student-designed, self-playing ukulele.

Through the course of this module, students employ a multidisciplinary approach to robotics using tools, methods, and procedures spanning a number of different engineering fields (electrical, mechanical, acoustical, and computing). Beyond the microcontroller and breadboard, the students are also responsible for procuring their own components, so they gain an appreciation for efficient project planning, shipping timelines, and other impediments to construction.

\section{Heat Engine 7WMP:}

This module involves an in-depth analysis of the gas laws (Charles's law, Boyle's Law, and Gay-Lussac's Law) and how these laws combine to give the familiar equation of state commonly known as the ideal gas law. Students validate each of the gas laws experimentally, using a piston/cylinder apparatus (shown in Figure 2A), and comparing measurements with predictions from the laws (Figure 2B shows an example of validation of Boyle's law). Students then predict the influence (if any) of the thermodynamic parameter being held constant for a given law. For example, Boyle's Law states that volume is inversely proportional to pressure at a fixed temperature. Students first record volume (by measuring height of piston inside the cylinder) as a function of pressure (pressure is changed by adding known masses atop the piston) at room temperature and find the slope of a plot of volume versus reciprocal pressure; they are then asked to predict what would happen if the experiment were performed at a hotter or colder temperature and then tasked with repeating the experiment under hot (air canister submerged in boiling water) and cold (air canister submerged in ice/water bath) conditions. The knowledge gained from the gas laws is then applied to understand the workings of a Stirling heat engine along with a tutorial on pressure-versus-volume diagrams for various heat engine cycles. Students are challenged to understand and explain the design of the displacer (size and position on the 
crankshaft) and the connection between engine efficiency and power on the temperatures of the heating source and sink.

Students in this module were expected to achieve the following CLOs:

1. Understand and validate the gas laws (Charles, Boyle, Gay-Lussac, Ideal gas) by comparing experiment (piston/cylinder apparatus) with theory.

2. Become familiar with engine cycles (Carnot, Ericsson, Stirling) and the corresponding pressure-volume diagrams.

3. Generate in real time experimental pressure-volume diagrams for the Ericsson and Stirling cycles using the same piston/cylinder apparatus as is used to validate the gas laws.

4. Calculate engine efficiencies.

5. Predict and measure how efficiency varies with temperatures of heat source and heat sink.

6. Demonstrate an understanding, both theoretical and practical, of how a Stirling engine operates.

7. Design a displacer for a Stirling engine that either makes the engine operational or improves its efficiency.
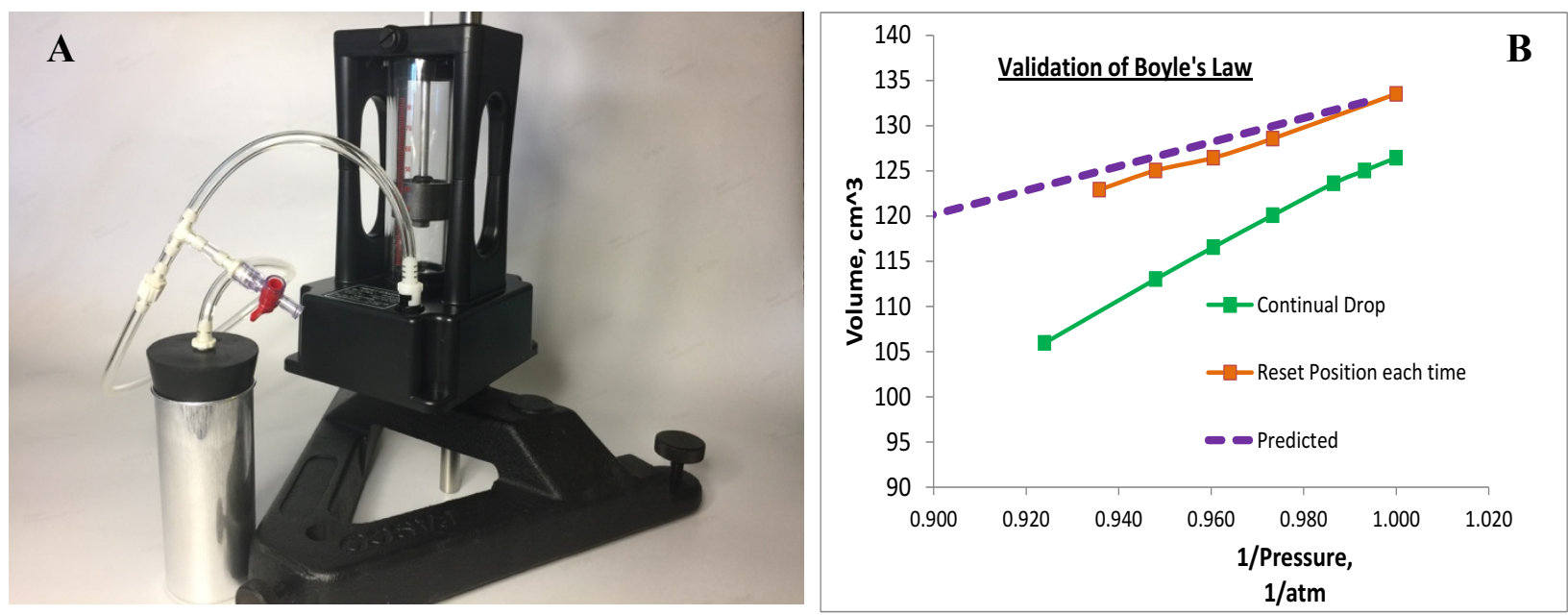

Figure 2: (A) The piston/cylinder apparatus; (B) Example data validating Boyle's law.

Supercap Car Challenge 7WMP:

In this module, students are introduced to several important engineering concepts and gain proficiency in many useful engineering techniques and tools. This module is designed to be an engineering design challenge. During the first few weeks of this 7WMP, students engage in structured activities leading up to less structured lab time to work on their own designs. After a few weeks of learning relevant equipment and techniques, students are tasked with creating a modified version of a standardized supercapacitor-powered toy car "Supercap Car", pictured in Figure $3 \mathrm{~A}$, which is given to each team of 3 or 4 students at the start of the module. Their redesigned car is then entered into a performance challenge at the end of the module. At the 
completion of this module, students will be able to demonstrate the following engineering learning outcomes:

1. successfully integrate digital and physical design.

2. use electronics prototyping tools in the design of a mechatronic system.

3. use modern fabrication tools in the design process.

4. make design choices based on fundamental physics and equipment characterization considerations.

The 7WMP example used in Table 2 shows the online lecture and lab activities for this project. During the last week of the module, students submit a one page "Design Brief" which communicates the design changes they employed, and the performance enhancement of their car, defined as the ratio of experimentally measured distance to the calculated distance.

Teams then participate in a "Distance Trial" where their car will have to make a turn past an obstacle and travel as far as possible on the limited power supplied by the supercapacitors. The Distance Trial layout is shown in Figure 3B, highlighting the path the car should take in the challenge, and denoting the various scoring regions. A detailed scoring breakdown for the challenge is provided to the students in a module overview document.

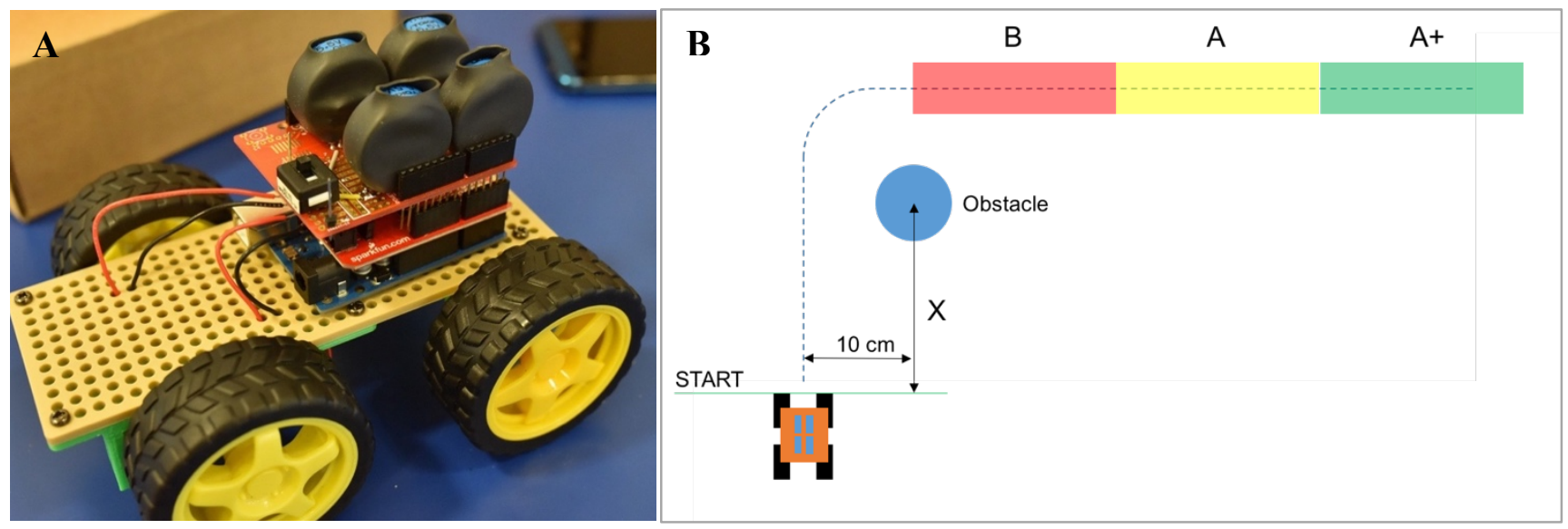

Figure 3: (A) Standard Supercap Car; (B) Distance Trial layout.

\section{Survey results}

In order to capture student perception of ability and performance in ENGR 101, a Likert-type survey $($ Excellent $=4 \ldots$ Poor $=1)$ was administered to both pilot and non-pilot sections of the course during the first week of the term and during the last week of the term with unique emails sent to each student enrolled at the time of the survey. An additional Likert-type survey (Strongly Agree $=5 \ldots$ Strongly Disagree $=1$ ) was provided to students in the pilot sections only during week 4 of the term.

During the fall quarter, surveys were sent out to all students registered for ENGR 101. The survey completion data is presented in Table 3, and lists the percentage of surveys completed. 
The post-course survey completion percentage for the college is typically around $33 \%$, so the significant change in completion percentage between the post-course survey and the other interm surveys was anticipated.

Table 3: Self-efficacy survey completion data.

\begin{tabular}{|l|c|c|}
\hline \multicolumn{1}{|c|}{ Survey } & $\begin{array}{c}\text { Surveys } \\
\text { completed }\end{array}$ & $\begin{array}{c}\text { Completion } \\
\text { percentage }\end{array}$ \\
\hline Pre-course survey & 648 & $81.10 \%$ \\
\hline Mid-course survey (pilot only) & 89 & $81.65 \%$ \\
\hline Post-course survey & 242 & $30.95 \%$ \\
\hline
\end{tabular}

Before and after the course, students from both pilot and non-pilot sections of the course were asked to self-report their ability to do each of the CLOs:

Students will be able to...

1. describe the engineering design process.

2. use the engineering design process to work through an engineering problem.

3. describe and use techniques for successful team management.

4. use analytical and computational modeling and/or visualization tools to describe the activities, tools and products of working engineers.

5. describe distinguishing characteristics among College of Engineering majors.

6. make measurements and analyze engineering data taking into consideration limits of measurement, uncertainty and errors.

7. demonstrate effective technical communication in oral, visual and written forms.

To more closely examine the effectiveness of the individual MPs and 7WMPs during the three pilot sections of ENGR 101, students completed a survey during week 4 of the term. In regards to MP1, the pilot section students were asked three questions regarding the usefulness of the associated online video lectures (whether or not the video lectures...improved teamwork, improved oral presentation skills, improved technical writing ability) and the average Likert scale score was 4.09, indicating they "Somewhat Agreed" that the online video lectures were useful in improving their teamwork, oral presentation, and technical writing abilities.

Lastly, students in the pilot sections were also asked to self-report their ability to do each of the CLOs specific to each 7WMP (see each module overview in "7WMP descriptions" section above) in both the pre-course survey and the post-course survey. Comparing student's selfreported abilities before and after the project, students taking the Robot Instruments module reported that the module increased their abilities (based on the CLOs for this module) by $70 \%$, students taking the Heat Engine module reported that the module increased their abilities (based on the CLOs for this module) by $81 \%$, and students taking The Supercap Car Challenge module reported that the module increased their abilities (based on the CLOs for this module) by $38 \%$. Comparing their self-reported ability to do each of the module-specific CLOs before and after completing their 7WMPs, there was an average improvement of $63.23 \%$ across all three 7WMPs. The data presented in Figure 4 are the sample mean values of the before and after surveys for both pilot and non-pilot sections. This data set, which is limited to only one term of ENGR 101, shows preliminarily that students feel the CLOs 1-7 are being met in both pilot and non-pilot 
sections; however, there is a slight improvement of $6.65 \%$ when comparing post-course impressions between pilot and non-pilot students (i.e., between post-course pilot and post-course non-pilot sections). Since the number of survey respondents varied between pilot and non-pilot sections, and between pre- and post- term surveys, error bars are included which represent the average standard error of the mean for each question presented in Figure 4. The standard error of the mean is computed as the standard deviation divided by the square root of the number of respondents for each question.

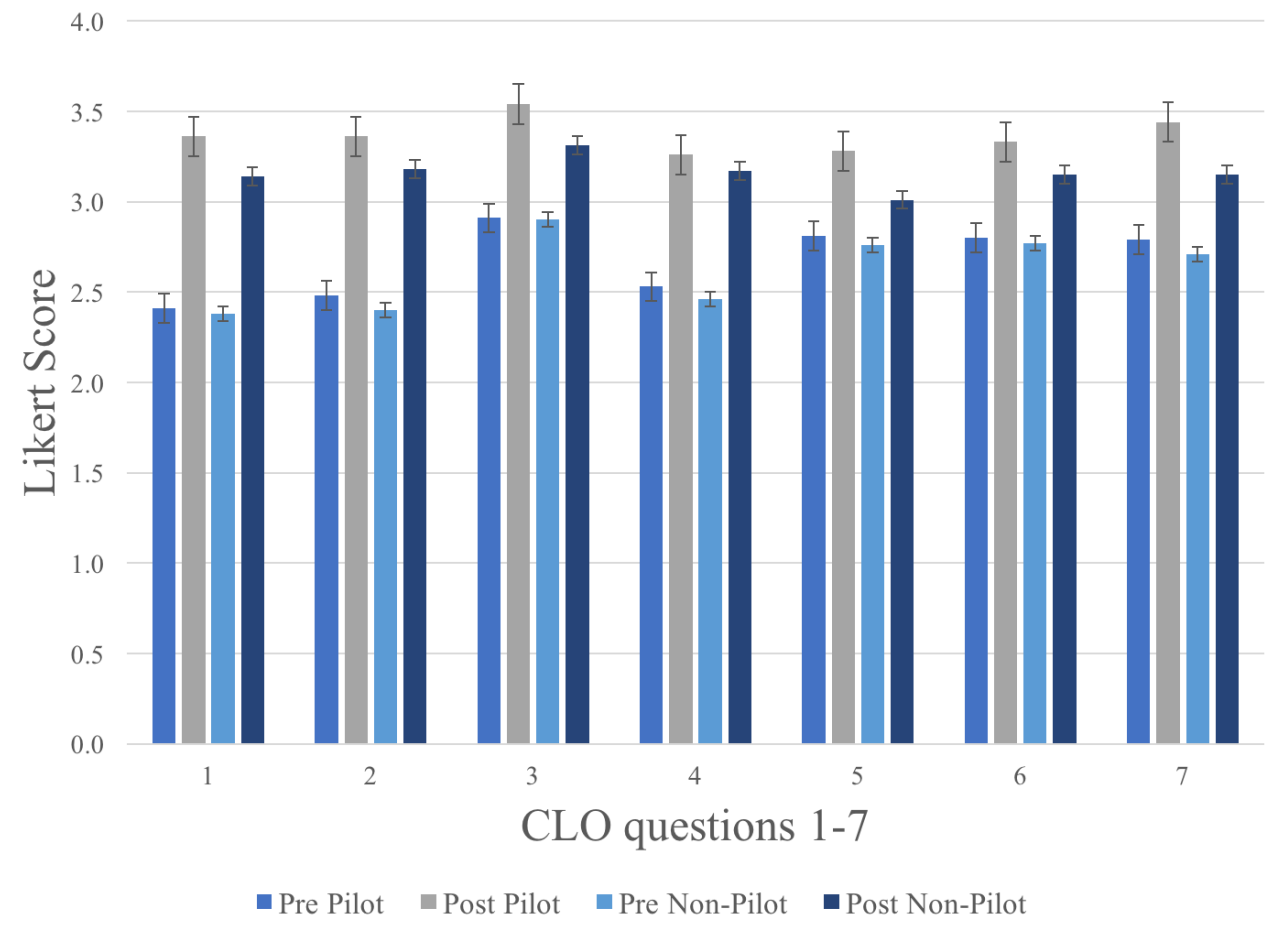

Figure 4: Self-reported achievement of CLOs before and after one quarter of ENGR 101 for both pilot and non-pilot sections.

\section{Future work}

The three 7WMP modules are to be repeated for the winter term of the same academic year with the variation that the ten-week term begins with a 7-week module and ends with MP2, focused on project planning, ethics, and presentation skills in the last three weeks. These latter concepts provide an opportunity for students to reflect upon and solidify the concepts learned from the fall quarter ENGR 101 course in addition to the winter term's first seven weeks of the ENGR 102 course. These last three weeks of core activities also serve to prepare the students for the third and final term of the first-year engineering core program, ENGR 103, as well as future engineering design endeavors. ENGR 103 requires the students to work on a team-based termlength project with less guidance from the instructors than in the previous two terms.

"Field testing" the pilot modules in the fall and winter quarters of the current academic year affords the authors/developers/committee the chance to collect and compile assessment results from both quarters, discuss the logistics and delivery formats, assess the success of the two-term 
pilot program, and appropriately plan the incorporation of the pilot modules into the general population of the first-year engineering design laboratory courses.

\section{References}

[1] B. M. Olds and R. L. Miller, "The effect of a first-year integrated engineering curriculum on graduation rates and student satisfaction: A longitudinal study," Journal of Engineering Education, vol. 93, p. 23, 2004.

[2] S. S. Courter, S. B. Millar, and L. Lyons, "From the students' point of view: Experiences in a freshman engineering design course," Journal of Engineering Education, vol. 87, pp. 283-288, 1998.

[3] D. W. Knight, L. E. Carlson, and J. F. Sullivan, "Staying in engineering: Impact of a handson, team-based, first-year projects course on student retention," Proceedings of the 2003

American Society for Engineering Education Annual Conference \& Exposition, vol. 8, p. 1, 2003.

[4] Cindy P. Veenstra, Eric L. Dey, and Gary D. Herrin. A model for freshman engineering retention. Advances in Engineering Education, 1(3):1-31, 2009.

[5] J.M. Paz, M. Cousins, C. D. Wilson, and M. K. Markey. Retention of first-year undergraduate engineering students: Role of psychosocial interventions targeting first-generation college students. In Proceedings of the 122nd ASEE Annual Conference and Exposition, Seattle, WA, June 2015.

[6] W. J. Palm, C. R. Thomas, Living-Learning Communities Improve First-Year Engineering Student Academic Performance and Retention at a Small Private University. In Proceedings of the 122nd ASEE Annual Conference and Exposition, Seattle, WA, June 2015.

[7] D. Wohlgemuth, et al., Financial, Academic, and Environmental Influences on the Retention and Graduation of Students. J. College Student Retention, Vol. 8(4): 457-475, 2006-2007.

[8] S. Lorimer and J. A. Davis. Using strengths of first-year engineering students to enhance teaching. Proceedings of the $122^{\text {nd }}$ ASEE Annual Conference and Exposition, Seattle, WA, June 2015 .

[9] Brian F. French, Jason C. Immekus, and William C. Oakes. An examination of indicators of engineering students' success and persistence. Journal of Engineering Education, 94(4):419-425, 2005.

[10] Tapia, Student Success through College of Engineering Freshman Year Experience Program. Proceedings of the $123^{\text {rd }}$ ASEE Annual Conference and Exposition, New Orleans, LA, June 2016. 
[11] Matthew Meyer and Sherry Marx. Engineering dropouts: A qualitative examination of why undergraduates leave engineering. Journal of Engineering Education, 103(4):525-548, 2014.

[12] Kerry L. Meyers, Stephen E. Silliman, Natalie L. Gedde, and MatthewW. Ohland. A comparison of engineering students' reflections on their first-year experiences. Journal of Engineering Education, 99(2):169-178, 2010.

[13] Clive L. Dym, Alice M. Agogino, Ozgur Eris, Daniel D. Frey, and Larry J. Leifer. Engineering design thinking, teaching, and learning. Journal of Engineering Education, 94(1):103-120, 2005.

[14] E. Fromm and R. Quinn, "An Experiment to Enhance The Educational Experience of Engineering Students,” Engineering Education, 79(3), 1989.

[15] J. E. Mitchell, "Institutionalization of E"," Proceedings of Frontiers in Education, San Jose, CA, November 1994.

[16] R. Caverly, et. al. Project-based Freshman Engineering Experience: The Core Course, Proceedings of the 2010 ASEE Annual Conference and Exposition, Louisville, KY, June 2010. 